\title{
Home mechanical ventilation: quality of life patterns after six months of treatment
}

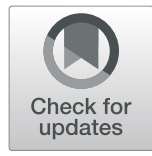

Luca Valko ${ }^{1 *} \mathbb{D}$, Szabolcs Baglyas ${ }^{1}$, V. Anna Gyarmathy ${ }^{2,3}$, Janos Gal' and Andras Lorx ${ }^{1}$

\begin{abstract}
Background: It has been shown that home mechanical ventilation improves quality of life, but it has not been widely studied which particular patient groups benefit the most from starting this type of therapy. The purpose of this prospective observational study was to evaluate quality of life change patterns 6 months after initiation of home mechanical ventilation in patients suffering from chronic respiratory failure using patient reported outcomes.

Methods: We enrolled 74 chronic respiratory failure patients starting invasive or noninvasive home mechanical ventilation through the Semmelweis University Home Mechanical Ventilation Program. Quality of life was evaluated at baseline and at 6 months after initiation of home mechanical ventilation using the Severe Respiratory Insufficiency Questionnaire.
\end{abstract}

Results: Overall quality of life showed $10.5 \%$ improvement 6 months after initiation of home mechanical ventilation $(p<0.001)$. The greatest improvement was observed in Respiratory complaint $(20.4 \%, p=0.015)$, Sleep and attendant symptoms $(19.3 \%, p<0.001)$, and Anxiety related subscales $(14.4 \%, p<0.001)$. Interface (invasive versus noninvasive ventilation) was not associated with improvement in quality of life ( $p=0.660)$. Severely impaired patients showed the greatest improvement $(C C=-0.328, p<0.001)$. Initial diagnosis contributed to the observed change ( $p=0.025)$, with chronic obstructive pulmonary disease and obesity hypoventilation syndrome patients showing the greatest improvement, while amyotrophic lateral sclerosis patients showed no improvement in quality of life. We found that patients who were started on long term ventilation in an acute setting, required oxygen supplementation and had low baseline quality of life, showed the most improvement during the six-month study period.

Conclusions: Our study highlights the profound effect of home mechanical ventilation on quality of life in chronic respiratory failure patients that is indifferent of ventilation interface but is dependent on initial diagnosis and some baseline characteristics, like acute initiation, oxygen supplementation need and baseline quality of life.

Trial registration: This study was approved by and registered at the ethics committee of Semmelweis University (SE TUKEB 251/2017; 20th of December, 2017).

Keywords: Home mechanical ventilation, Quality of life change, Chronic respiratory failure, Long term ventilation, Domiciliary ventilation

\footnotetext{
* Correspondence: valko.luca@med.semmelweis-univ.hu

${ }^{1}$ Department of Anesthesiology and Intensive Therapy, Semmelweis University, Ulloi ut 78/B, Budapest 1082, Hungary

Full list of author information is available at the end of the article
}

(c) The Author(s). 2020 Open Access This article is licensed under a Creative Commons Attribution 4.0 International License, which permits use, sharing, adaptation, distribution and reproduction in any medium or format, as long as you give appropriate credit to the original author(s) and the source, provide a link to the Creative Commons licence, and indicate if changes were made. The images or other third party material in this article are included in the article's Creative Commons licence, unless indicated otherwise in a credit line to the material. If material is not included in the article's Creative Commons licence and your intended use is not permitted by statutory regulation or exceeds the permitted use, you will need to obtain permission directly from the copyright holder. To view a copy of this licence, visit http://creativecommons.org/licenses/by/4.0/ The Creative Commons Public Domain Dedication waiver (http://creativecommons.org/publicdomain/zero/1.0/) applies to the data made available in this article, unless otherwise stated in a credit line to the data. 


\section{Background}

Chronic respiratory failure affects many people, causing hypoxia, hypercapnia, secondary symptoms, diminished health related quality of life (HRQL) and adverse outcomes. Long term mechanical ventilation, which can be supplied through a noninvasive (mask) or invasive interface (tracheostomy) if noninvasive ventilation is contraindicated or not feasible (e.g. in the case of bulbar symptoms), improves outcomes in many different types of chronic respiratory failure [1-3]. Home mechanical ventilation (HMV) reduces costs, infection rates, optimizes medical care utilization and perhaps most importantly for the patients, improves HRQL [4]. Hence home mechanical ventilation has been an increasing practice worldwide $[5,6]$. As guidelines do not include specific ventilation goals and settings, practice varies greatly in different regions [7]. Because of this, HRQL measurements are important tools for quality control, optimization of therapy and even outcome prediction [8].

HRQL is usually measured through questionnaires and as general health quality surveys might be inaccurate in specific diseases groups, there have been attempts to establish a more focused questionnaire useful in chronic respiratory failure patients [9-11]. Perhaps the most efficient questionnaire for this purpose designed up until now is the SRI Questionnaire, which is a multimodal tool with high psychometric properties, specifically designed to evaluate HRQL in patients battling chronic respiratory conditions [12]. The SRI Questionnaire has been validated in several different conditions and has been proven to be a superior HRQL evaluation tool for patients receiving home mechanical ventilation $[9,13]$. The questionnaire has been used to evaluate HRQL in both invasively and noninvasively ventilated patients and has been validated in several different languages, including Hungarian [13-21].

The effect of starting home mechanical ventilation on patients' HRQL has been studied before, but these studies either used a general HRQL survey [22] or focused only on a well-defined, selected population often excluding patients with tracheostomas, or patients that were recruited after inability to wean or after an acute worsening of their chronic condition [13]. As a considerable proportion of home mechanical ventilation patients are started on long term therapy after acute exacerbation or failure to wean from ventilatory support, these studies might not reflect real-life populations, as more severe patients are underrepresented (see Table 1). Studies have also shown that HRQL differs greatly in chronic respiratory failure patients with different diseases (see Table 1) and we can expect that the change in HRQL induced by home mechanical ventilation also varies $[7,10,13,14]$. The factors that can possibly affect change in HRQL are baseline characteristics, initial diagnosis, initial HRQL, type of interface used for ventilation, duration of ventilation and lung function test parameters. Studies performed on specific patient groups might have different follow-up plans, and their HRQL changes might not be comparable.

To our knowledge, no prospective study has examined one specific HMV protocol and its HRQL improving effects in a large, unselected case mix population.

The aim of this study was to describe the effect of initiation of protocolized, optimally conducted home mechanical ventilation with standardized follow-up in a real-life, mixed case group of chronic respiratory patients using a disease specific HRQL survey and to evaluate expected HRQL change patterns for these patients.

\section{Methods}

\section{Study design and participants}

The purpose of this prospective observational follow-up study was to evaluate, using the Hungarian validated version of the Severe Respiratory Insufficiency Questionnaire [21], HRQL change 6 months after the initiation of home mechanical ventilation in patients suffering from chronic respiratory failure, and identify possible factors influencing said changes. We enrolled patients diagnosed with chronic respiratory failure in need for long term mechanical ventilation, who were treated through the Semmelweis University Home Mechanical Ventilation Program from January 2014 to December 2018. Patients were referred to the Program either through elective workup for a chronic condition (elective initiation) or after recovery from a previously unknown chronic condition (acute initiation). All patients were enrolled based on work up during stable conditions and diagnosed according to available international guidelines [1-3]. Patients who were unable to complete the questionnaire were excluded. Patients who deceased before the study completion were noted as lost to follow up. Written informed consent was obtained from all patients included in the study. The study was approved by the ethics committee of Semmelweis University.

\section{Home mechanical ventilation initiation and follow-up}

Home mechanical ventilation was initiated according to the Semmelweis University Home Mechanical Ventilation Program Guideline either after discharge from an acute hospitalization or during an elective hospital admission. Given the current reimbursement system utilized in Hungary, patients have the benefit of receiving patient tailored ventilation plans and equipment supply, including cough assisting devices, if needed. Mechanical ventilation was supplied through A40 or Trilogy 100 home mechanical ventilators (Koninklijke Philips N.V., 
Table 1 Studies utilizing SRI to report detailed HRQL for HMV patients

\begin{tabular}{|c|c|c|c|c|}
\hline Author & Study aim & & Patients & $\begin{array}{l}\text { Main HRQL (SRI SS) finding } \\
\text { for HMV patients }\end{array}$ \\
\hline Windisch et al. [13] & $\begin{array}{l}\text { Studies reporting change } \\
\text { in } \mathrm{HRQL}\end{array}$ & $\begin{array}{l}\text { HRQL improvement } \\
\text { during HMV }\end{array}$ & 85 stable NIV patients & $\begin{array}{l}49 \pm 15 \text { (baseline) } \\
61 \pm 15 \text { (1 month) } \\
61 \pm 16 \text { (1 year) }\end{array}$ \\
\hline Struik et al. [23] & & $\begin{array}{l}\text { NIV vs. standard } \\
\text { treatment }\end{array}$ & $\begin{array}{l}108 \text { COPD patients after } \\
\text { acute exacerbation }\end{array}$ & $\begin{array}{l}47.9 \pm 15.1 \text { (baseline) } \\
55.0 \pm 15.4 \text { (12 months) }\end{array}$ \\
\hline Murphy et al. [24] & & $\begin{array}{l}\text { O2 therapy vs NIV } \\
+\mathrm{O} 2 \text { therapy }\end{array}$ & $\begin{array}{l}64 \text { hypercapnic patients } \\
\text { after acute exacerbation }\end{array}$ & 50.6 (6 weeks) \\
\hline Howard et al. [25] & & CPAP vs Bi-level PAP & $\begin{array}{l}57 \text { OHS patients (outpatient } \\
\text { or hospital referral) }\end{array}$ & $\begin{array}{l}50.63 \pm 3.65 \text { (baseline) } \\
63.5 \pm 3.74 \text { (3 months) }\end{array}$ \\
\hline Storre et al. [26] & & AVAPS in OHS & $\begin{array}{l}10 \text { OHS patients starting } \\
\text { NIV }\end{array}$ & $\begin{array}{l}63 \pm 15 \text { (baseline) } \\
78 \pm 14 \text { (6 weeks BPV-S/T) } \\
76 \pm 16 \text { (6 weeks BPV-S/T-AVAPS) }\end{array}$ \\
\hline Murphy [27] & $\begin{array}{l}\text { Studies reporting HRQL for a } \\
\text { specific HMV patient group }\end{array}$ & $\begin{array}{l}\text { High intensity vs high } \\
\text { pressure NIV }\end{array}$ & $\begin{array}{l}7 \text { COPD with established } \\
\text { HMV }\end{array}$ & $57 \pm 11$ vs $69 \pm 16$ \\
\hline Storre et al. [28] & & $\begin{array}{l}\text { High intensity vs target } \\
\text { volume NIV }\end{array}$ & $\begin{array}{l}10 \text { COPD patients with } \\
\text { established HMV }\end{array}$ & $59.3 \pm 14.8$ vs $62.4 \pm 18.9$ \\
\hline Arellano-Maric et al. [29] & & NIV vs CPAP & $\begin{array}{l}42 \mathrm{OHS} \text { patients with } \\
\text { established NIV }\end{array}$ & $61.2 \pm 16$ vs $65.3 \pm 14$ \\
\hline Windisch [30] & & SRI validation in COPD & $\begin{array}{l}162 \text { COPD patients with } \\
\text { established NIV }\end{array}$ & $52 \pm 17$ \\
\hline Walterspracher [31] & & SRI for LOT COPD patients & $\begin{array}{l}42 \text { COPD patients with } \\
\text { established NIV }\end{array}$ & $53.2 \pm 18.6$ \\
\hline Oga et al. [11] & & HRQL tool comparisons & $\begin{array}{l}56 \text { COPD/TB patients } \\
\text { with established NIV }\end{array}$ & $56.0 \pm 15.3$ \\
\hline Chen et al. [18] & & Chinese SRI validation & 149 stable NIV patients & $52.93 \pm 15.11$ \\
\hline Budweiser [8] & $\begin{array}{l}\text { Studies reporting HRQL for } \\
\text { mixed HMV patient group }\end{array}$ & Prognostic value of $\mathrm{HRQL}$ & $\begin{array}{l}231 \text { stable IV and IV } \\
\text { patients }\end{array}$ & $\begin{array}{l}61.2 \pm 17.7 \text { (all patients) } \\
52.2 \pm 15.6 \text { (COPD) } \\
66.2 \pm 17.2 \text { (RCWD) } \\
55.3 \pm 9.2(\mathrm{NMD}) \\
71.3 \pm 15.7 \text { (OHS/OL) }\end{array}$ \\
\hline Gosh et al. [16] & & English SRI validation & $\begin{array}{l}152 \text { stable NIV and IV } \\
\text { patients }\end{array}$ & $\begin{array}{l}55.9 \pm 18.9 \text { (all patients) } \\
43.1 \pm 17.3 \text { (COPD) } \\
61.9 \pm 16.1 \text { (RCWD) } \\
58.8 \pm 20.3 \text { (NMD) } \\
53.4 \pm 18.8 \text { (OHS) } \\
53.5 \pm 19.7 \text { (miscellaneous) }\end{array}$ \\
\hline Oga et al. [19] & & Japanese SRI validation & 56 stable NIV patients & $\begin{array}{l}56.0 \pm 15.3 \text { (all patients) } \\
56.6 \pm 14.7 \text { (COPD) } \\
55.5 \pm 16.4 \text { (Tb) }\end{array}$ \\
\hline Ribeiro et al. [20] & & Portuguese SRI validation & $\begin{array}{l}93 \text { stable NIV and IV } \\
\text { patients }\end{array}$ & $\begin{array}{l}56.6 \pm 15.7 \text { (all patients) } \\
57.0 \pm 16.5 \text { (COPD) } \\
55.6 \pm 15.1 \text { (OHS) } \\
62.0 \pm 12.6 \text { (RCWD) } \\
50.2 \pm 16.2 \text { (COPD+OSA) } \\
59.4 \pm 19.2 \text { (NMD) } \\
46.0 \pm 13.3 \text { (miscellaneous) }\end{array}$ \\
\hline Markussen et al. [17] & & Norwegian SRI validation & $\begin{array}{l}127 \text { stable NIV and IV } \\
\text { patients }\end{array}$ & $\begin{array}{l}55.8 \pm 18.4 \text { (all patients) } \\
61.0 \pm 14.7 \text { (NMD) } \\
43.2 \pm 19.0 \text { (COPD) } \\
58.4 \pm 18.3 \text { (OHS) } \\
55.8 \pm 18.4 \text { (RCWD) }\end{array}$ \\
\hline Valko et al. [21] & & Hungarian SRI validation & $\begin{array}{l}104 \text { stable NIV and IV } \\
\text { patients }\end{array}$ & $\begin{array}{l}66.8 \pm 15.1(\mathrm{NIV}) \\
58.2 \pm 13.6(\mathrm{IV})\end{array}$ \\
\hline Huttmann et al. [32] & & $\begin{array}{l}\text { HRQL after unsuccessful } \\
\text { weaning }\end{array}$ & 25 IV patients & $\begin{array}{l}49 \pm 16(\mathrm{NMD}) \\
47 \pm 20 \text { (COPD) }\end{array}$ \\
\hline Huttmann et al. [14] & & $\begin{array}{l}\text { HRQL of invasively ventilated } \\
\text { HMV patients }\end{array}$ & $32 \mathrm{IV}$ patients & $\begin{array}{l}53 \pm 16 \text { (all patients) } \\
58 \pm 16 \text { (NMD) }\end{array}$ \\
\hline
\end{tabular}


Table 1 Studies utilizing SRI to report detailed HRQL for HMV patients (Continued)

\begin{tabular}{llll}
\hline Author & Study aim & Patients & $\begin{array}{l}\text { Main HRQL (SRI SS) finding } \\
\text { for HMV patients }\end{array}$ \\
\hline & & & $48 \pm 15$ (lung diseases) \\
Raveling et al. [33] & Hypercapnia improvement & 240 COPD patients & $49.9 \pm 15.0$ (all patients) \\
& as a survival predictor & starting NIV & $54.6 \pm 14.3$ (stable patients) \\
& & $47.9 \pm 14.9$ (patients after ARF)
\end{tabular}

Data are presented as mean (SD)

NIV noninvasive ventilation, IV invasive ventilation, HRQL health related quality of life, HMV home mechanical ventilation, SRI SS Severe Respiratory Insufficiency Questionnaire Summary Score, COPD chronic obstructive pulmonary disease, $T B$ tuberculosis sequelae, OHS obesity hypoventilation syndrome, OL overlap syndrome, NMD neuromuscular disease, $R C D W$ restrictive chest wall disease, BPV-S/T bilevel pressure ventilation -spontaneous/timed, $A V A P S$ average volume assured pressure support

Amsterdam) and built in, AIRcon or HC150 humidifiers (WILAmed GmbH, Kammerstein; Fishel Paykel Healthcare, Auckland) in pressure controlled, volume targeted mode through a noninvasive interface if possible or invasive interface if noninvasive ventilation was contraindicated or not feasible. Inspiratory time was aimed at $25 \%$ for patients with obstructive lung function characteristics and 30\% for all other patients, then further tuned for optimal patient comfort. Supplementary $\mathrm{O}_{2}$ was applied if arterial blood gas values showed a $\mathrm{p}_{\mathrm{a}} \mathrm{O}_{2}$ below $60 \mathrm{mmHg}$. Treatment goals for home mechanical ventilation were normalization of $\mathrm{p}_{\mathrm{a}} \mathrm{CO}_{2}$ and $\mathrm{p}_{\mathrm{a}} \mathrm{O}_{2}$ blood gas levels and adequate respiratory secretion management. Patients received individually tailored therapy with adequate interface (nasal, full, total face masks or cuffed tracheostomy tubes with reusable inner cannula), personalized daily ventilation plans and cough assisting device (CoughAssist T70, Koninklijke Philips N.V., Amsterdam) and/or tracheal suction devices if peak expiratory flows were below $2.5 \mathrm{~L} / \mathrm{s}$, suggesting insufficient coughing. Home mechanical ventilation was overseen by a voluntary family member or caregiver trained by our institution in skills specific to the patient's treatment plan. Patients did not receive other institutionalized assistance. Optimal care was achieved by frequent physician follow up to achieve high compliance with therapy and continuously maintained treatment goals. Patients were followed up monthly or bimonthly by a physician of the program, trained in home mechanical ventilation. Data were not routinely collected for the purpose of this study during these physician visits.

\section{Data collected}

Demographic data (age, sex, initial diagnosis), treatment characteristics (initiation type, interface, daily ventilation need, $\mathrm{O}_{2}$ supplementation need), arterial blood gas values and lung function tests were collected at baseline, ventilator settings and blood gas values (if feasible) were collected at 6 months. Arterial blood gas sampling was performed minimum $15 \mathrm{~min}$ after discontinuing ventilation and/or oxygen supplementation, unless patients were ventilator dependent and could not be disconnected for even short periods of time. Lung function tests were performed with the Piston PinkFlow meter (Piston Ltd., Budapest, Hungary). Initial diagnosis leading to chronic respiratory failure and long-term mechanical ventilation need was identified as chronic obstructive pulmonary disease (COPD), restrictive chest wall disease (RCWD), obesity hypoventilation syndrome (OHS), slowly progressing neuromuscular disease (NMD) or progressive neuromuscular disease (amyotrophic lateral sclerosis) (ALS).

\section{HRQL assessment}

HRQL was assessed at baseline and 6 months after initiation of home mechanical ventilation using the Hungarian version of the SRI Questionnaire. The questionnaire consists of 49 statements and a five-point Likert scale. The results are interpreted in 7 different subscales (SRI-RC: Respiratory complaints, SRI-PF: Physical functioning, SRI-AS: Attendant symptoms and sleep, SRI-SR: Social relationships, SRI-AX: Anxiety, SRI-WB: Psychological well-being and SRI-SF: Social functioning) and the Summary Score (SRI-SS), with a value between 0 to 100 , with 100 being the highest score. Patients were asked to fill out self-administered questionnaires and were assisted by caregivers if physical limitation or eyesight problems prohibited participation. The baseline questionnaire was filled out and collected during participating patients' hospital stay, while the follow-up questionnaires were collected by the visiting physician. Patients referred to our Program after acute hospitalization were asked to base their baseline answers on the last month prior to their acute illness to reflect chronic health status.

\section{Statistical analysis}

Continuous variables are described with means and standard deviation $( \pm \mathrm{SD})$ and categorical variables with frequencies and percentages ( $\mathrm{n}$ and \%). SRI scores were analyzed with Paired t-test or, in case of non-normally distributed data, Signed Rank Test. Characteristics were compared with t-test or, in case of non-normally distributed data, Mann-Whitney U Rank sum test. Diagnostic 
groups were compared with one-way ANOVA (BrownForsythe) or, in case of non-normally distributed data, ANOVA on Ranks. Pearson Product Moment Correlation was used for correlation analysis. A $p$-value of $<0.05$ was considered statistically significant. Analyses were conducted using SigmaPlot 12 (Systat Software, San Jose, United States) and SPSS Statistics for Windows 25 (IBM Corp., Armonk, NY). Bubble charts, commonly used to depict more complex, multidimensional correlations visually, were used to visualize quality of life change patterns in the following three dimensions: 1) size representing extent of change (larger bubbles mean larger changes), 2) texture representing direction of change (bubbles with - sign representing negative change, while bubbles with no texture representing positive change), and 3) shading representing significance (non-significant bubbles are white, while significant bubbles are gray). Bubble charts were created in Microsoft Excel.

\section{Results}

\section{Patients}

Out of the 75 patients enrolled, 2 were excluded because they were unable to complete HRQL forms due to cognitive impairment. One patient was deceased before study completion, and 6 patients were excluded because of missing data. A total of 66 patients completed the study.

Baseline characteristics of the patients are listed in Table 2.

Indication for invasive ventilation was bulbar symptoms in 10 (71.4\%) and more than $16 \mathrm{~h}$ of ventilation in $4(28.6 \%)$ of the 14 cases in the study. Invasively ventilated patients had higher daily ventilation need $(17.9( \pm 6.5)$ vs. $11.1( \pm 5.8)$ hours, $p<0.001)$, lower FVC\% (31.5 $( \pm 23.3)$ vs $51.1( \pm 20.3), p=0.004)$ and PEF\% $(23.9( \pm 20.9)$ vs $39.6( \pm 19.4), p=0.013)$ values, but had corrected blood gas parameters $\left(\mathrm{pO}_{2}: 78.4( \pm 16.8)\right.$ vs $67.4( \pm 12.7), p=0.016 ; \mathrm{pCO}_{2}: 36.2( \pm 7.3)$ vs $53.2( \pm 17.7)$, $p=0.001)$ compared to noninvasively ventilated patients at baseline.

Patients initiated after acute hospitalization had no significant differences in baseline ventilation need, supplementary oxygen need, lung function or blood gas values compared to those enrolled electively.

Compliance remained stable during the study duration, with slightly diminishing daily ventilator use at 6 months $(12.6( \pm 6.6)$ vs $11.2( \pm 6.6)$ hours, $p<0.001)$. Blood gas parameters showed improvement from baseline values $\left(\mathrm{pO}_{2}: 69.7( \pm 14.2)\right.$ vs $73.7( \pm 14.3), p=$ $0.011 ; \mathrm{pCO}_{2}: 49.7( \pm 17.5)$ vs $45.1( \pm 11.4), p=0.005$; $\mathrm{HCO}_{3}: 28.0( \pm 5.2)$ vs $\left.26.9( \pm 3.3), p=0.038\right)$, despite decrease in $\mathrm{O}_{2}$ supplement use $(1.8( \pm 2.8)$ vs $1.3( \pm 2.2)$, $p=0.011$ ).

\section{Baseline HRQL}

Overall SRI score was $57.7( \pm 14.4)$ and several subscales showed values under 60, corresponding to limited HRQL with SRI-RC, -PF, -AS, -WB and -SF being the aspects with the lowest values (Fig. 1).

\section{Differences in baseline HRQL scores by interface and diagnosis}

As can be seen from Fig. 1, none of the baseline SRI subscales differed in patients treated through invasive or noninvasive interface. Baseline SRI-AS and -AX subscales were significantly associated with initial diagnosis ( $p=0.048$ and $p=0.018$ respectively). The SRI-AS scores were the lowest in OHS and ALS patients, while SRI-AX scores were the lowest in COPD and ALS patients (Fig. 1).

\section{Differences in baseline $H R Q L$ scores by initiation type and $\mathrm{O}_{2}$ need}

In addition, there was no difference in baseline SRI scores in patients initiated acutely compared to those initiated electively, or in patients needing $\mathrm{O}_{2}$ supplementation compared to patients who did not. Furthermore, SRI subscales showed no correlation with initial blood gas values, lung function test parameters, or hours of ventilation need (data not shown).

\section{Overall HRQL change at 6-month follow-up}

There was an $10.5 \%$ overall improvement of SRI summary scores from baseline to six-months $(57.7 \pm 14.4$ vs. $68.2 \pm 15.8, p<0.001)$. All SRI subscales showed significant improvement during the first 6 months of home mechanical ventilation (Table 3.)

\section{Factors effecting HRQL change $H R Q L$ change by interface and diagnosis}

As can be seen from Fig. 2, the choice of interface did not affect change in SRI subscales $(p=0.660)$. Changes in SRI-RC, $-\mathrm{PF},-\mathrm{SF}$ and $-\mathrm{SS}$ subscales were significantly influenced by initial diagnosis $(p=0.025, p<0.001, p=$ 0.002 and $p=0.025$ respectively).

When further analyzing HRQL changes within diagnostic groups, we found that different diagnostic groups had different HRQL change patterns, which is visualized in the bubble chart depicting relative changes in different patient groups (Fig. 3). As can be seen from the figure, the patients benefiting most from HMV were COPD patients, while OHS patients improved across the most SRI subscales. SRI-RC subscale improved in all groups but ALS patients, and most prominently in COPD and OHS patients. SRI-PF and -AX scores improved only in COPD and OHS patients. SRI-SR subscales showed no change in any of the patient groups, except for OHS patients. SRI-WB and-SF 
Table 2 Baseline demographics and patient characteristics

\begin{tabular}{|c|c|}
\hline Characteristic & mean (SD) or $\mathrm{n}(\%)$ \\
\hline Total & $66(100 \%)$ \\
\hline \multicolumn{2}{|l|}{ Gender } \\
\hline Female & $20(30.3 \%)$ \\
\hline Male & $46(69.7 \%)$ \\
\hline Age (years) & $51.5( \pm 18.1)$ \\
\hline \multicolumn{2}{|l|}{ Initiation of ventilation } \\
\hline Acute & $40(60.6 \%)$ \\
\hline Elective & $24(39.4 \%)$ \\
\hline \multicolumn{2}{|l|}{ Interface } \\
\hline Invasive & $14(21.2 \%)$ \\
\hline Noninvasive & $52(78.8 \%)$ \\
\hline \multicolumn{2}{|l|}{$\mathrm{O}_{2}$ supplementation need } \\
\hline No & $33(50 \%)$ \\
\hline Yes & $33(50 \%)$ \\
\hline $\mathrm{O}_{2}$ flow $(\mathrm{L} / \mathrm{min})$ & $1.8( \pm 2.8)$ \\
\hline Daily ventilation need (hours) & $12.6( \pm 6.5)$ \\
\hline \multicolumn{2}{|l|}{ Ventilator settings } \\
\hline Target volume $(\mathrm{mL})$ & $541( \pm 129)$ \\
\hline Inspiratory pressure $(\mathrm{cmH} 2 \mathrm{O})$ & $22.2( \pm 4.8)$ \\
\hline Exspiratory pressure $(\mathrm{cmH} 2 \mathrm{O})$ & $8.3( \pm 3.6)$ \\
\hline Frequency (/min) & $15.9( \pm 3.6)$ \\
\hline \multicolumn{2}{|l|}{ Initial diagnosis } \\
\hline Chronic obstructive pulmonary disease & $9(13.6 \%)$ \\
\hline Restrictive chest wall disease & $5(7.6 \%)$ \\
\hline Obesity hypoventilation syndrome & $20(30.3 \%)$ \\
\hline Non progressive neuromuscular disease & $19(28.8 \%)$ \\
\hline $\begin{array}{l}\text { Progressive neuromuscular disease } \\
\text { (amyotrophic lateral sclerosis) }\end{array}$ & $13(19.7 \%)$ \\
\hline \multicolumn{2}{|l|}{ Lung function } \\
\hline FVC\% & $47.2( \pm 22.2)$ \\
\hline FEV1\% & $38.7( \pm 21.3)$ \\
\hline FEV1/FVC\% & $86.0( \pm 21.8)$ \\
\hline PEF\% & $36.5( \pm 20.6)$ \\
\hline \multicolumn{2}{|l|}{ Arterial blood gas } \\
\hline $\mathrm{p}_{\mathrm{a}} \mathrm{O}_{2}(\mathrm{mmHg})$ & $69.7( \pm 14.2)$ \\
\hline $\mathrm{p}_{\mathrm{a}} \mathrm{CO}_{2}(\mathrm{mmHg})$ & $49.7( \pm 17.5)$ \\
\hline $\mathrm{HCO}_{3}(\mathrm{mmol} / \mathrm{L})$ & $28( \pm 5.2)$ \\
\hline
\end{tabular}

Data are presented as mean (SD) for continuous and as percentages (n) for categorical variables. Lung function parameters are presented as percentage of expected value

FVC forced vital capacity, FEV1 forced expiratory volume in $1 \mathrm{~s}$, PEF peak expiratory flow

improved only in OHS, and SRI-SF actually declined significantly in ALS patients. Overall SRI-SS scores improved in all patient groups except for ALS (see also Additional file 1).

\section{$H R Q L$ change by initiation type, $\mathrm{O}_{2}$ need, and baseline} $H R Q L$

Summary score improved significantly more in patients initiated acutely compared to patients initiated electively $(12.3 \pm 16.8$ vs. $7.4 \pm 9.4, p=0.029)$. Change in SRI subscales showed no correlation with initial blood gas values, lung function test parameters or hours of ventilation need (data not shown). In patients using $\mathrm{O}_{2}$ supplementation SRI-PF, -SF and -SS subscales improved significantly compared to patients that did not require $\mathrm{O}_{2}$ supplementation (SRI-PF: $13.1 \pm 25.5$ vs. $-1.0 \pm 25.0$ $p=0.001$; SRI-SF: $9.2 \pm 21.9$ vs. $0.6 \pm 20.3, p=0.022$; SRISS: $12.0 \pm 15.6$ vs. $9.0 \pm 13.8, p=0.006)$.

When further analyzing factors affecting HRQL changes in patients receiving home mechanical ventilation, we found that change in SRI subscales showed significant correlation with baseline SRI scores (SRI-RC: $p<0.001 ; \mathrm{CC}=-0.782$; SRI-PF: $p=0.0314 ; \mathrm{CC}=-0.265$; SRI-AS $p<0.001 ; \quad C C=-0.769 ; \quad$ SRI-SR: $p=0.006$; $\mathrm{CC}=-0.336$; SRI-AX: $p<0.001 ; \mathrm{CC}=-0.559$; SRI-WB: $p<0.001 ; \mathrm{CC}=-0.465 ;$ SRI-SF: $p=0.007 ; \mathrm{CC}=-0.328$; SRI-SS: $\quad p \quad<0.001 ; \quad \mathrm{CC}=-0.411$ ) (Fig. 4). This phenomenon was most prominent in SRI-RC and SRI-AS scales.

\section{Discussion}

The aim of our study was to assess HRQL change induced in a mixed case chronic respiratory failure patient population in one HMV center. Our cohort included patients with a variety of underlying conditions, ventilated both invasively and noninvasively, initiated acutely and electively, resulting in a real-life study population. Frequent follow up visits ensured optimal compliance and maintained treatment goals, ensuring that HRQL changes were comparable despite the mixed case study population.

We found that overall HRQL improved significantly in the first 6 months of home mechanical ventilation and the grade of HRQL change was influenced by initial diagnosis. Furthermore, we also found that patients with worse initial HRQL, initiated acutely and needing $\mathrm{O}_{2}$ supplementation, had a greater improvement in HRQL and that HRQL did not improve in ALS patients but was maintained despite significant progression of the disease.

The group of patients recruited for this study had baseline characteristics similar to home mechanical ventilation populations described before (see Tables 1 and 2). Noninvasively ventilated patient populations have been known to be characterized by a daily ventilation need of 6.5 to $9 \mathrm{~h}, \mathrm{FVC} \%$ values of $42-62 \%, \mathrm{pO}_{2}$ of $66-$ $73 \mathrm{Hgmm}$, and $\mathrm{pCO}_{2}$ of 44-59, while invasively ventilated patients have been reported to have higher daily ventilation needs $(18-20 \mathrm{~h})$, with $\mathrm{O}_{2}$ supplementation needed in $75 \%$ of patients $[12-14,22]$. In our study 


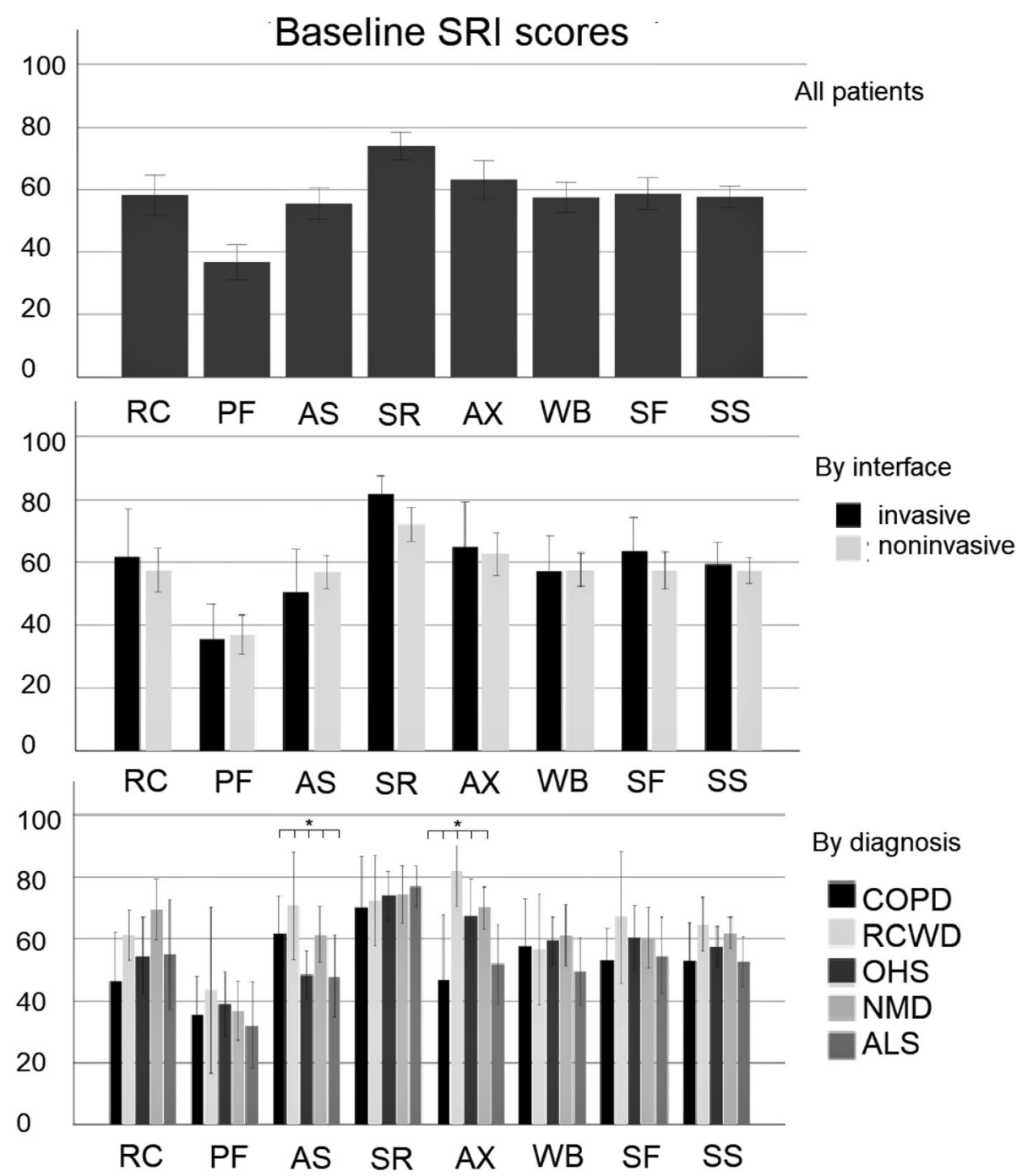

Fig. 1 Bar graphs of baseline scores of the SRI subscales for the whole study group, by interface and by diagnosis. Boxes represent means, error bars represent standard error. Significant differences are marked with asterisk. COPD: chronic obstructive pulmonary disease, RCWD: restrictive chest wall disease, OHS: obesity hypoventilation syndrome, NMD: neuromuscular disease, ALS: amyotrophic lateral sclerosis, RC: Respiratory complaints, PF: Physical functioning, AS: Attendant symptoms and sleep, SR: Social relationships, AX: Anxiety WB: Psychological well-being, SF: Social functioning, SS: Summary Score

Table $3 \mathrm{HRQL}$ subscale values before and 6 months after initiation of home mechanical ventilation

\begin{tabular}{lllr}
\hline & Quality of life before home mechanical ventilation & Quality of life 6 months after initiation of home mechanical ventilation & $p=0.015^{*}$ \\
RC & $58.3( \pm 25.9)$ & $78.7( \pm 17.3)$ & $p<0.001^{*}$ \\
PF & $36.7( \pm 22.5)$ & $42.8( \pm 29.6)$ & $p=0.006^{*}$ \\
AS & $55.5( \pm 20.6)$ & $74.8( \pm 14.0)$ & $p<0.001^{*}$ \\
SR & $74.1( \pm 18.1)$ & $76.2( \pm 18.4)$ & $p<0.001^{*}$ \\
AX & $63.3( \pm 25.0)$ & $77.7( \pm 22.6)$ & $p<0.001^{*}$ \\
WB & $57.5( \pm 19.7)$ & $63.8( \pm 19.3)$ & $p<0.001^{*}$ \\
SF & $58.7( \pm 21.1)$ & $63.6( \pm 24.6)$ & $p<0.001^{*}$ \\
SS & $57.7( \pm 14.4)$ & $68.2( \pm 15.8)$ &
\end{tabular}

Significant differences are marked with asterisk

$R C$ Respiratory complaints, PF Physical functioning, AS Attendant symptoms and sleep, SR Social relationships, AX Anxiety, WB Psychological well-being, SF Social functioning, SS Summary Score 


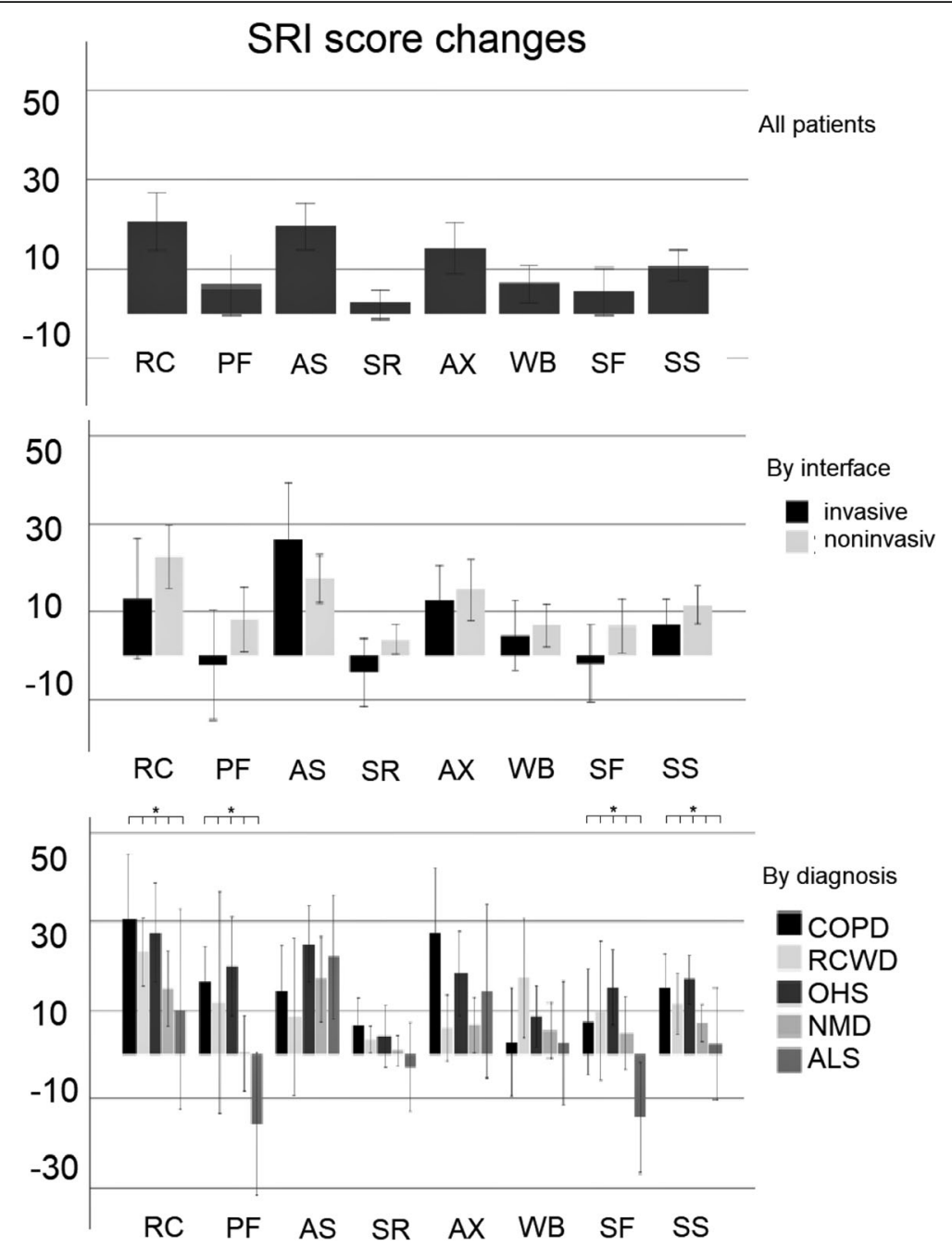

Fig. 2 Bar graphs of changes in the scores of SRI subscales at the 6-month follow-up in the whole study group, by interface and by diagnostic groups. Boxes represent means, error bars represent standard error. Significant differences are marked with asterisk. COPD: chronic obstructive pulmonary disease, RCWD: restrictive chest wall disease, OHS: obesity hypoventilation syndrome, NMD: neuromuscular disease, ALS: amyotrophic lateral sclerosis, RC: Respiratory complaints, PF: Physical functioning, AS: Attendant symptoms and sleep, SR: Social relationships, AX: Anxiety WB: Psychological well-being, SF: Social functioning, SS: Summary Score

population, invasive and noninvasive ventilation ratio was similar to proportions noted in the Eurovent study describing patterns of HMV in Europe [5]. This ratio explains the mean daily ventilator use in our study as well as the high $\mathrm{O}_{2}$ supplementation need. Lung function tests and blood gas values at baseline were consistent with values described in the previous references, with mean values showing restrictive lung function changes, hypoxia and hypercapnia $[12-14,22]$. The majority of patients were initiated on HMV after resolution of an acute exacerbation of a previously undiagnosed chronic condition, which might be explained by possible insufficient diagnostic algorithms and screening of patient populations with higher risk of chronic respiratory failure.

Baseline HRQL in our study population was similar (SRI-SS: $57.7 \pm 14.4$ ) to values described in patients suffering from chronic respiratory failure (see Table 1), with the subscales of Respiratory complaints, Attendant symptoms and sleep, Physical functioning, Social functioning and Psychological well-being being the aspects most diminished. To our knowledge, no previous study compared patients ventilated invasively versus patients ventilated noninvasively, although patients ventilated through a tracheostomy are generally assumed to have diminished HRQL $[14,34]$. In our study population none of the baseline SRI subscales differed in patients treated through invasive or noninvasive interface, in patients initiated acutely or electively or in patients needing $\mathrm{O}_{2}$ supplementation compared to patients who did not, and SRI subscales showed no correlation with initial blood gas values, lung function test parameters or hours of ventilation need, pointing to the fact that HRQL is 


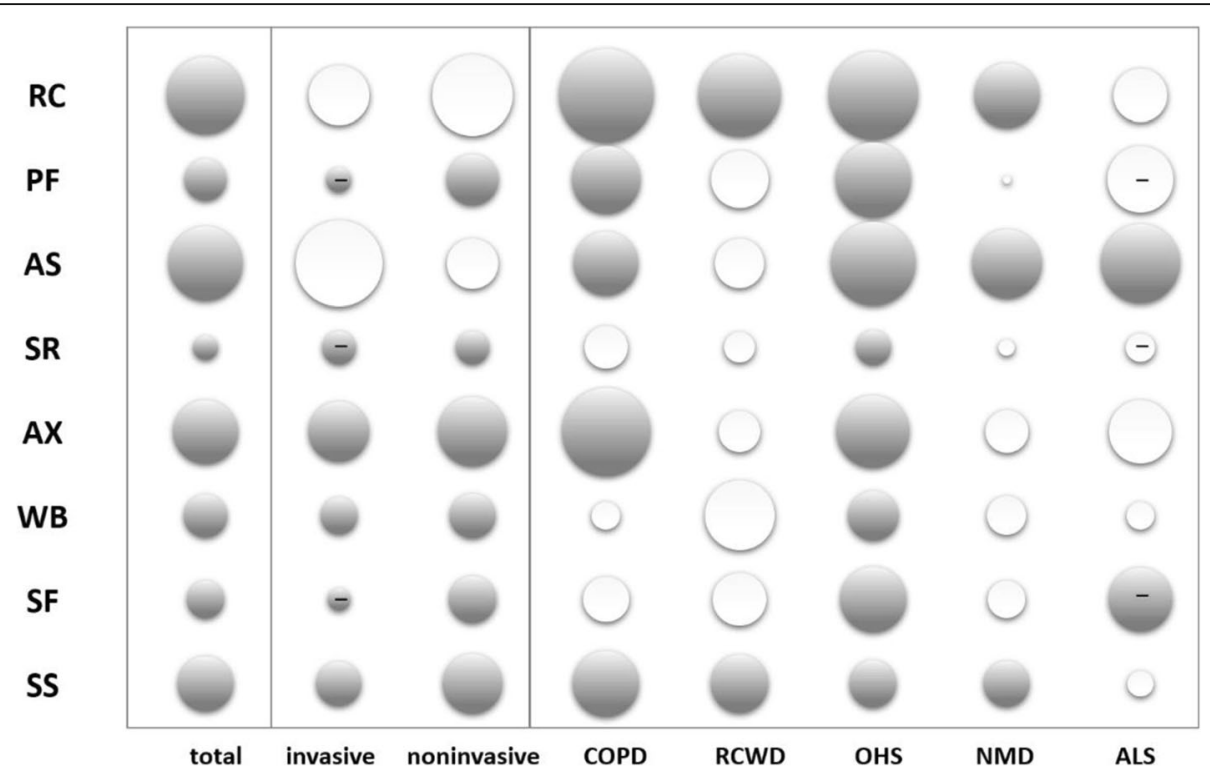

Fig. 3 Bubble chart of SRI subscale changes for the whole study group and according to interface and diagnosis after 6 months of home mechanical ventilation. Size corresponds to value of change from baseline. Significant changes are marked with gray shading. Negative changes are marked by negative sign pattern. COPD: chronic obstructive pulmonary disease, RCWD: restrictive chest wall disease, OHS: obesity hypoventilation syndrome, NMD: neuromuscular disease, ALS: amyotrophic lateral sclerosis, RC: Respiratory complaints, PF: Physical functioning, AS: Attendant symptoms and sleep, SR: Social relationships, AX: Anxiety WB: Psychological well-being, SF: Social functioning, SS: Summary Score

not merely influenced by the severity of respiratory failure, although the relatively low number of invasively ventilated patients might contribute to this finding.

We found that quality of life increased significantly during the six-month observation period (SRI summary score changed from $57.7 \pm 14.4$ vs. $68.2 \pm 15.8, p<$ 0.001 ), which is similar to changes reported by studies in more selective patient populations (see Table 1). HRQL subscales that were most robustly improved were Respiratory complaints and Attendant symptoms and sleep, which are indeed the main goals of long-term mechanical ventilation. Anxiety subscales also showed significant improvement, which is most likely a consequence of the improvement of the two prior scales. Social relations and Social functioning showed no change, which suggests that these subscales are influenced by more complex disease attributes and are not solely related to respiratory symptoms. The change in Physical functioning also showed no significant overall improvement, which is understandable since several patient groups had stable or progressive neuromuscular impairment. When looking at specific disease groups, we found that diseases where neuromuscular involvement was not present (COPD and OHS), Physical functioning subscale actually improved significantly and considerably $(16.2 \pm 12.2, p=0.002$ and $19.8 \pm 24.9, \quad p<0.001$ respectively).

The overall SRI HRQL change found in our study is similar to changes previously reported in a study using solely noninvasive ventilation [13]. Furthermore, our study found higher post-ventilation HRQL values than a study in a population ventilated invasively [14]. As an additional interesting finding, our study suggests that an increase in HRQL does not depend on interface [35], meaning HRQL can both be increased through invasive and noninvasive ventilation. This is important because there is a general fear towards tracheostomy in patients requiring long term mechanical ventilation [36]. The results of our study provide evidence that significant improvement might be achieved in HRQL even through an invasive interface. This can be attributed to patienttailored home mechanical ventilation therapy, which is feasible under current reimbursement system in Hungary and permits complex ventilation and physiotherapy plans for patients, despite vastly different needs. The other possible reason for the consistently improved outcome might be the frequent follow-ups provided by our program. Current international guidelines do not specify the frequency of follow up for home mechanically ventilated patients [1-3], but most centers reduce the frequency of home or ambulatory visits to twice a year after successful initiation [4, 7]. In our patient population, however, follow-up was provided monthly for patients ventilated invasively and monthly or bimonthly for stable patients ventilated through a noninvasive interface.

When looking at other factors potentially influencing HRQL change, we found that HRQL increase was the 


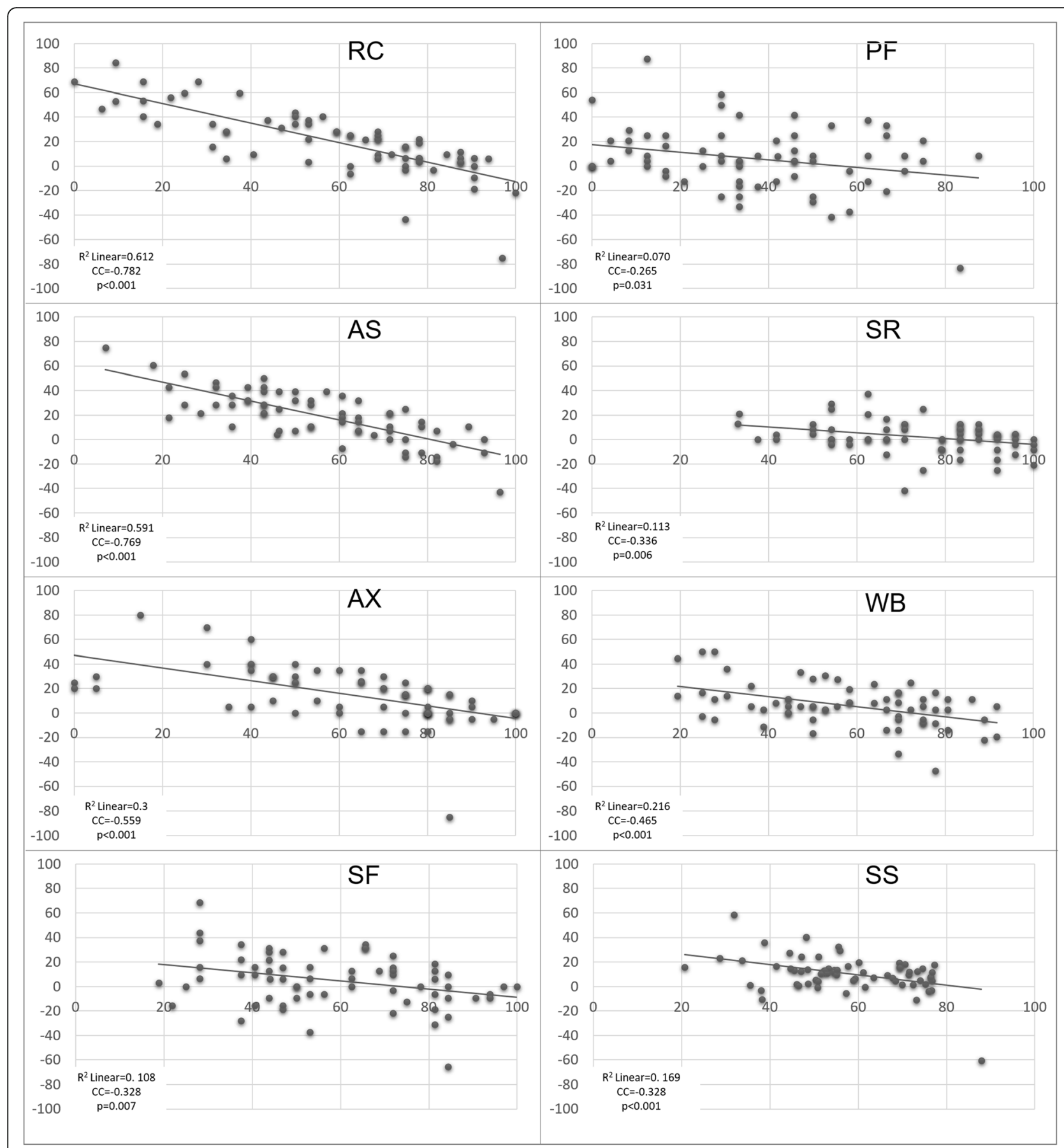

Fig. 4 Subscale changes in relation to baseline subscales. Scatterplot of SRI subscale changes according to initial SRI values. X axis shows change of SRI subscale. Y axis shows initial SRI subscale value. R² Linear: coefficient of determination, CC: correlation coefficient, RC: Respiratory complaints, PF: Physical functioning, AS: Attendant symptoms and sleep, SR: Social relationships, AX: Anxiety WB: Psychological well-being, SF: Social functioning, SS: Summary Score

greatest among patients with lower initial HRQL scores, patients initiated with long term mechanical ventilation in an acute setting, and patients needing supplemental $\mathrm{O}_{2}$ therapy, implying that a lot of patients included in the current study might have received home mechanical ventilation relatively late in their course of disease progression. This is corroborated by the study previously published by our group that describes the current characteristics and prevalence of HMV in Hungary [37], which found that prevalence of home mechanical ventilation is lower than that found in other internationally published data, because many ventilator-dependent 
patients might not receive therapy in time. This finding is especially important, since there is still no clear data to help us differentiate between long term therapeutic home mechanical ventilation and palliative care with ventilation. The results of our study suggest that even patients with very poor HRQL benefit greatly from initiation of home mechanical ventilation.

Our results regarding the HRQL influencing effect of initial diagnosis corroborate the findings published previously $[13,14]$. Based on our findings, COPD patients can expect the most benefit in HRQL increase, which is important, since long term home mechanical ventilation is still controversial in this indication [38-40], although it should be noted that COPD is a heterogenous disease group and our study did not analyze disease phenotypes. Moreover, when analyzing patient groups, we found that OHS patients improved most consistently, on par with recently published guidelines [41]. Given that this disease effects a younger population and its main symptoms are debilitating daytime sleepiness and hypercapnia [42], this HRQL improvement has important socioeconomical consequences. It is also important to note that recent guidelines indicate most OHS patients might be managed with initial CPAP therapy. Prospective HRQL change studies might verify whether optimal improvement can be achieved by this approach.

In our study, the only patient group not showing improved HRQL scores were the ALS patients, which is on par with literature describing this progressive neuromuscular disease [43], although noninvasive ventilation has been shown to improve HRQL and even survival for a shorter period of time [44]. In our study, spanning a longer period, it is especially conspicuous that ALS patients were the only ones to show significant detriment in one subscale (SRI Social functioning change), suggesting that these patients often become isolated during the progression of their disease. However, it is noteworthy that despite HRQL subscale changes due to disease progression, overall Summary scores remained stable, mainly because Attendant symptoms and sleep, Anxiety and Respiratory complaints subscales counterbalance the decrease in Social functioning and Physical functioning subscales. This suggests that home mechanical ventilation might be a valid palliative care technique in ALS even in cases where significant lifespan or HRQL improvement can't be proven.

The main limitation of our study is the sample size that might be considered small; however previously published studies on HMV patients utilized similar sample sizes $[11,13,14,21,23]$. Our study was a single center, prospective HRQL change investigation under optimized care using the SRI Questionnaire, providing valuable "real-life" information on a mixed case population previously not extensively described in the literature. Another limitation is that the study was not designed to identify outcome differences in patients with different interfaces or initial diagnosis, nor was powered for multivariate analysis to exactly define confounding factors influencing subscale changes, as subgroup analysis would have resulted in groups that would have been too small to deduct relevant clinical correlations.

\section{Conclusions}

Starting home mechanical ventilation is accompanied by improved quality of life in several patient groups suffering from chronic respiratory failure. Our findings suggest that HRQL improvement is independent of classic markers of the severity of chronic respiratory failure (e.g., baseline lung function, arterial blood gas value, hours of ventilation need) or interface used for ventilation, but it is dependent on the type of disease causing the chronic respiratory failure, initiation type (acute versus elective), initial HRQL and $\mathrm{O}_{2}$ supplementation need. Our results further suggest that acutely initiated, $\mathrm{O}_{2}$ dependent COPD and OHS patients with low initial HRQL can expect the most benefit, while ALS patients can expect maintenance of overall HRQL despite ongoing neurological deterioration. Further prospective studies are needed to confirm our findings and to identify whether HRQL changes correlate with disease progression and mortality, and how often HRQL needs to be measured during the follow up of patients receiving home mechanical ventilation in order to better improve the lives of patients suffering from chronic respiratory failure.

\section{Supplementary information}

Supplementary information accompanies this paper at https://doi.org/10. 1186/s12890-020-01262-z.

Additional file 1. HRQL subscale changes according to diagnostic groups. Contains exact numerical HRQL subscale changes according to diagnostic groups with significant values noted.

\footnotetext{
Abbreviations

ALS: Amyotrophic lateral sclerosis; ANOVA: Analysis of variance; AVAP S: Average volume assured pressure support; BPV-S/T: Bilevel pressure ventilation -spontaneous/timed; CC: Correlation coefficient; COPD: Chronic obstructive pulmonary disease; FEV1: Forced expiratory volume in $1 \mathrm{~s}$; FVC: Forced vital capacity; HMV: Home mechanical ventilation; HRQL: Health related quality of life; NMD: Neuromuscular disease; OHS: Obesity hypoventilation syndrome; $\mathrm{p}_{\mathrm{a}} \mathrm{CO}_{2}$ : Arterial partial pressure of carbon dioxide; $\mathrm{p}_{\mathrm{a}} \mathrm{O}_{2}$ : Arterial partial pressure of oxygen; PEF: Peak expiratory flow; RCWD: Restrictive chest wall disease; SD: Standard deviation; SRIQ: Severe Respiratory Insufficiency Questionnaire; SRI-AS: Attendant symptoms and sleep; SRI-AX: Anxiety; SRI-PF: Physical functioning; SRI-RC: Respiratory complaints; SRI-SF: Social functioning; SRI-SR: Social relationships; SRISS: Summary Score; SRI-WB: Psychological well-being
} 


\section{Authors' contributions}

LV, SB and AL designed the study. LV, SB and AL collected data. LV, SB and AL analyzed and interpreted the data. LV, AL, VAG and JG contributed to the writing of the manuscript. All authors read and approved the final manuscript.

\section{Funding}

No outside funding was utilized during this study.

\section{Availability of data and materials}

The datasets used and analyzed during the current study are available from the corresponding author on reasonable request.

\section{Ethics approval and consent to participate}

The study was approved by the research ethics board of Semmelweis University (SE TUKEB 251/2017). Participation was voluntary and informed written consent was obtained from all participants. All procedures performed involving human participants were in accordance with the ethical standards of the institutional and/or national research committee and with the 1964 Helsinki Declaration and its later amendments or comparable ethical standards.

\section{Consent for publication}

Not applicable.

\section{Competing interests}

The authors declare that they have no conflict of interest.

\section{Author details}

'Department of Anesthesiology and Intensive Therapy, Semmelweis University, Ulloi ut 78/B, Budapest 1082, Hungary. ${ }^{2}$ EpiConsult, Dover, DE, USA. ${ }^{3}$ Johns Hopkins Bloomberg School of Public Health, Károly Racz School of PhD Studies, Semmelweis University, 8 the Green, STE A, Dover, DE 19904 USA.

Received: 12 May 2020 Accepted: 10 August 2020

Published online: 17 August 2020

\section{References}

1. McKim DA, Road J, Avendano M, Abdool S, Cote F, Duguid N, Fraser J, Maltais F, Morrison DL, O'Connell C, et al. Home mechanical ventilation: a Canadian thoracic society clinical practice guideline. Can Respir J. 2011; 18(4):197-215

2. Windisch W, Geiseler J, Simon K, Walterspacher S, Dreher M. German National Guideline for treating chronic respiratory failure with invasive and non-invasive ventilation: revised edition 2017 - part 1. Respiration. 2018; 96(1):66-97.

3. Windisch W, Geiseler J, Simon K, Walterspacher S, Dreher M. German National Guideline for treating chronic respiratory failure with invasive and non-invasive ventilation - revised edition 2017: part 2. Respiration. 2018; 96(2):171-203.

4. Maclntyre EJ, Asadi L, MCKim DA, Bagshaw SM. Clinical outcomes associated with home mechanical ventilation: a systematic review. Can Respir J. 2016; 2016:6547180

5. Lloyd-Owen SJ, Donaldson GC, Ambrosino N, Escarabill J, Farre R, Fauroux B, Robert D, Schoenhofer B, Simonds AK, Wedzicha JA. Patterns of home mechanical ventilation use in Europe: results from the Eurovent survey. Eur Respir J. 2005;25(6):1025-31.

6. Goodwin S, Smith H, Langton Hewer S, Fleming P, Henderson AJ, Hilliard T, Fraser J. Increasing prevalence of domiciliary ventilation: changes in service demand and provision in the south west of the UK. Eur J Pediatr. 2011; 170(9):1187-92.

7. Hannan LM, Sahi H, Road JD, MCDonald CF, Berlowitz DJ, Howard ME. Care practices and health-related quality of life for individuals receiving assisted ventilation. A cross-National Study. Ann Am Thorac Soc. 2016;13(6):894-903.

8. Budweiser S, Hitzl AP, Jorres RA, Schmidbauer K, Heinemann F, Pfeifer M Health-related quality of life and long-term prognosis in chronic hypercapnic respiratory failure: a prospective survival analysis. Respir Res. 2007;8(1):92

9. Struik FM, Kerstjens HA, Bladder G, Sprooten R, Zijnen M, Asin J, van der Molen T, Wijkstra PJ. The severe respiratory insufficiency questionnaire scored best in the assessment of health-related quality of life in chronic obstructive pulmonary disease. J Clin Epidemiol. 2013;66(10):1166-74.

10. Oga T, Windisch W, Handa T, Hirai T, Chin K. Health-related quality of life measurement in patients with chronic respiratory failure. Respir Investig. 2018;56(3):214-21.

11. Oga T, Taniguchi $H$, Kita H, Tsuboi T, Tomii $K$, Ando M, Kojima E, Tomioka H, Taguchi Y, Kaji Y, et al. Comparison of different disease-specific healthrelated quality of life measurements in patients with long-term noninvasive ventilation. Can Respir J. 2017;2017:8295079.

12. Windisch W, Freidel K, Schucher B, Baumann H, Wiebel M, Matthys H, Petermann $F$. The severe respiratory insufficiency (SRI) questionnaire: a specific measure of health-related quality of life in patients receiving home mechanical ventilation. J Clin Epidemiol. 2003;56(8):752-9.

13. Windisch $\mathbf{W}$. Impact of home mechanical ventilation on health-related quality of life. Eur Respir J. 2008:32(5):1328-36.

14. Huttmann SE, Windisch W, Storre JH. Invasive home mechanical ventilation: living conditions and health-related quality of life. Respiration. 2015;89(4): 312-21.

15. Lopez-Campos JL, Failde I, Masa JF, Benitez-Moya JM, Barrot E, Ayerbe R, Leon-Jimenez A, Windisch W. Transculturally adapted Spanish SRI questionnaire for home mechanically ventilated patients was viable, valid, and reliable. J Clin Epidemiol. 2008;61(10):1061-6.

16. Ghosh D, Rzehak P, Elliott MW, Windisch W. Validation of the English severe respiratory insufficiency questionnaire. Eur Respir J. 2012;40(2):408-15.

17. Markussen H, Lehmann S, Nilsen RM, Natvig GK. The Norwegian version of the severe respiratory insufficiency questionnaire. Int J Nurs Pract. 2015; 21(3):229-38.

18. Chen R, Guan L, Wu W, Yang Z, Li X, Luo Q, Liang Z, Wang F, Guo B, Huo Y, et al. The Chinese version of the severe respiratory insufficiency questionnaire for patients with chronic hypercapnic chronic obstructive pulmonary disease receiving non-invasive positive pressure ventilation. BMJ Open. 2017;7(8):e017712.

19. Oga T, Taniguchi H, Kita H, Tsuboi T, Tomii K, Ando M, Kojima E, Tomioka H, Taguchi Y, Kaji Y, et al. Validation of the Japanese severe respiratory insufficiency questionnaire in hypercapnic patients with noninvasive ventilation. Respir Investig. 2017:55(2):166-72.

20. Ribeiro C, Ferreira D, Conde S, Oliveira P, Windisch W. Validation of the Portuguese severe respiratory insufficiency questionnaire for home mechanically ventilated patients. Rev Port Pneumol. 2017;23(3):139-45.

21. Valko L, Baglyas S, Kunos L, Terray-Horvath A, Lorx A, Gal J, Windisch W. Validation of the Hungarian version of the SRI questionnaire. BMC Pulm Med. 2020;20(1):130.

22. Tsolaki V, Pastaka C, Kostikas K, Karetsi E, Dimoulis A, Zikiri A, Koutsokera A Gourgoulianis Kl. Noninvasive ventilation in chronic respiratory failure: effects on quality of life. Respiration. 2011;81(5):402-10.

23. Struik FM, Sprooten RT, Kerstjens HA, Bladder G, Zijnen M, Asin J, Cobben NA, Vonk JM, Wijkstra PJ. Nocturnal non-invasive ventilation in COPD patients with prolonged hypercapnia after ventilatory support for acute respiratory failure: a randomised, controlled, parallel-group study. Thorax. 2014;69(9):826-34

24. Murphy PB, Rehal S, Arbane G, Bourke S, Calverley PMA, Crook AM, Dowson L, Duffy N, Gibson GJ, Hughes PD, et al. Effect of home noninvasive ventilation with oxygen therapy vs oxygen therapy alone on hospital readmission or death after an acute COPD exacerbation: a randomized clinical trial. JAMA. 2017;317(21):2177-86.

25. Howard ME, Piper AJ, Stevens B, Holland AE, Yee BJ, Dabscheck E, Mortimer $D$, Burge AT, Flunt D, Buchan $C$, et al. A randomised controlled trial of CPAP versus non-invasive ventilation for initial treatment of obesity hypoventilation syndrome. Thorax. 2017:72(5):437-44.

26. Storre JH, Seuthe B, Fiechter R, Milioglou S, Dreher M, Sorichter S, Windisch $W$. Average volume-assured pressure support in obesity hypoventilation: a randomized crossover trial. Chest. 2006;130(3):815-21.

27. Murphy PB, Brignall K, Moxham J, Polkey MI, Davidson AC, Hart N. High pressure versus high intensity noninvasive ventilation in stable hypercapnic chronic obstructive pulmonary disease: a randomized crossover trial. Int J Chron Obstruct Pulmon Dis. 2012;7:811-8.

28. Storre JH, Matrosovich E, Ekkernkamp E, Walker DJ, Schmoor C, Dreher M, Windisch W. Home mechanical ventilation for COPD: high-intensity versus target volume noninvasive ventilation. Respir Care. 2014;59(9):1389-97.

29. Arellano-Maric MP, Hamm C, Duiverman ML, Schwarz S, Callegari J, Storre JH, Schmoor C, Spielmanns M, Galetke W, Windisch W. Obesity 
hypoventilation syndrome treated with non-invasive ventilation: Is a switch to CPAP therapy feasible? Respirology. 2020;25(4):435-42.

30. Windisch W, Budweiser S, Heinemann F, Pfeifer M, Rzehak P. The severe respiratory insufficiency questionnaire was valid for COPD patients with severe chronic respiratory failure. J Clin Epidemiol. 2008;61 (8):848-53.

31. Walterspacher S, July J, Kohlhäufl M, Rzehak P, Windisch W. The severe respiratory insufficiency questionnaire for subjects with COPD with longterm oxygen therapy. Respir Care. 2016;61(9):1186-91.

32. Huttmann SE, Magnet FS, Karagiannidis C, Storre JH, Windisch W. Quality of life and life satisfaction are severely impaired in patients with long-term invasive ventilation following ICU treatment and unsuccessful weaning. Ann Intensive Care. 2018;8(1):38

33. Raveling T, Bladder G, Vonk JM, Nieuwenhuis JA, Verdonk-Struik FM, Wijkstra PJ, Duiverman ML. Improvement in hypercapnia does not predict survival in COPD patients on chronic noninvasive ventilation. Int J Chron Obstruct Pulmon Dis. 2018;13:3625-34.

34. Marchese S, Lo Coco D, Lo Coco A. Outcome and attitudes toward home tracheostomy ventilation of consecutive patients: a 10-year experience. Respir Med. 2008;102(3):430-6.

35. Markstrom A, Sundell K, Lysdahl M, Andersson G, Schedin U, Klang B. Quality-of-life evaluation of patients with neuromuscular and skeletal diseases treated with noninvasive and invasive home mechanical ventilation. Chest. 2002;122(5):1695-700

36. Rabkin J, Ogino M, Goetz R, McElhiney M, Hupf J, Heitzman D, HeimanPatterson T, Miller R, Katz J, Lomen-Hoerth C, et al. Japanese and American ALS patient preferences regarding TIV (tracheostomy with invasive ventilation): a cross-national survey. Amyotroph Lateral Scler Frontotemporal Degener. 2014;15(3-4):185-91.

37. Valko L, Baglyas S, Gal J, Lorx A. National survey: current prevalence and characteristics of home mechanical ventilation in Hungary. BMC Pulmon Med. 2018;18(1):190

38. Kohnlein T, Windisch W, Kohler D, Drabik A, Geiseler J, Hartl S, Karg O, LaierGroeneveld G, Nava S, Schonhofer B, et al. Non-invasive positive pressure ventilation for the treatment of severe stable chronic obstructive pulmonary disease: a prospective, multicentre, randomised, controlled clinical trial. Lancet Respir Med. 2014;2(9):698-705.

39. Ankjaergaard KL, Tonnesen P, Laursen LC, Hansen EF, Andreassen HF, Wilcke JT. Home non invasive ventilation (NIV) treatment for COPD patients with a history of NIV-treated exacerbation; a randomized, controlled, multi-center study. BMC Pulmon Med. 2016;16:32.

40. Dretzke J, Moore D, Dave C, Mukherjee R, Price MJ, Bayliss S, Wu X, Jordan $\mathrm{RE}$, Turner AM. The effect of domiciliary noninvasive ventilation on clinical outcomes in stable and recently hospitalized patients with COPD: a systematic review and meta-analysis. Int J Chron Obstruct Pulmon Dis. 2016; 11:2269-86.

41. Randerath W, Verbraecken J, Andreas S, Arzt M, Bloch KE, Brack T, Buyse B, De Backer W, Eckert DJ, Grote L, et al. Definition, discrimination, diagnosis and treatment of central breathing disturbances during sleep. Eur Respir J. 2017:49(1):1600959.

42. Piper A. Obesity hypoventilation syndrome: weighing in on therapy options. Chest. 2016;149(3):856-68.

43. Ng L, Khan F, Young CA, Galea M. Symptomatic treatments for amyotrophic lateral sclerosis/motor neuron disease. Cochrane Database Syst Rev. 2017;1: Cd011776.

44. Bourke SC, Tomlinson M, Williams TL, Bullock RE, Shaw PJ, Gibson GJ. Effects of non-invasive ventilation on survival and quality of life in patients with amyotrophic lateral sclerosis: a randomised controlled trial. Lancet Neurol. 2006;5(2):140-7.

\section{Publisher's Note}

Springer Nature remains neutral with regard to jurisdictional claims in published maps and institutional affiliations.

Ready to submit your research? Choose BMC and benefit from:

- fast, convenient online submission

- thorough peer review by experienced researchers in your field

- rapid publication on acceptance

- support for research data, including large and complex data types

- gold Open Access which fosters wider collaboration and increased citations

- maximum visibility for your research: over $100 \mathrm{M}$ website views per year

At BMC, research is always in progress.

Learn more biomedcentral.com/submissions 